tional ; in A. fragilis it seems to be the normal condition. My reason for this opinion is that the nephridial papilla, which appears to function as a penis, is present in all individuals. This papilla is much larger in $A$. fragilis than in any other Acmsa with which I am acquainted, reaching even in the contracted state almost to the edge of the mantle; it is highly muscular and richly provided with large blood sinuses. These facts point to its use as an intromittent organ and if this be conceded, then its universal presence would indicate that every individual is at some time functionally a male.

But however this may be, hermaphroditism either as a regular or as an exceptional condition has already been described in two Docoglossa so that the case of Bathysciadium is the third rather than the first recorded instance.

M. A. Willcox.

WooD's HoLL, MASS, July 25, 1900.

\section{SOME RECENT REPORTS OF FOREIGN MUSEUMS.}

THE report of the South African Museum for 1899 notes the completion of a new wing and the opening of a new hall containing a collection of South African rocks, minerals and fossils, while the number of visitors was over 88,000 , a gain of 7000 over the previous year. As the appropriation for the Museum is only $£ 2500$ the increase of the collections is mainly dependent on gifts, and although a special appropriation of $£ 2000$ for the purchase of specimens was made in 1895 this is now exhausted. The progress made is as rapid as could be hoped for under the circumstances, but one can well sympathize with the remark of Mr. Peringuey, in charge of the entomological collections, that the chance of obtaining a thorough representation of the insect fauna of South Africa during the modest span of life usually allotted to man, seems to grow more and more distant.

The Museum has just issued the first part of the second volume of its Annals which is devoted to 'A Collection of Slugs from South Africa, with Descriptions of New Species' by Walter E. Collinge. Two well-known species are added to the fauna of South Africa while four species are described as new ; Amalia pon- senbyi, Apera natalensis, Oopelta favescens and o. granulosa.

THE report of the Museum of Oxford University for 1899 indicates much progress in educational work and scientific research, as well as in the growth and arrangement of the collections. Three new buildings are in course of construction, the Laboratory of Animal Morphology and Botany, the Pathological Laboratory and the Radcliffe Library." Accessions to the well-known Pitt-Rivers Museum of Ethnology have been the most numerous, although exceeded in number of individual specimens by the insects added to the Hope Collection in charge of Professor Poulton. Our own scientific schools may derive some comfort from the small number of students who seem to have attended many of the courses of lectures, and when Professor Tylor reports a class varying from four to six undergraduates others have little reason to expect more.

PART one of volume three of the Boletim do Museu Paraense contains the report of the Director for the fiscal year ending December 31, 1898, together with other papers. The Zoological and Botanical Gardens of Para are included in this report and these, as well as the Museum proper, seem to be in a flourishing condition, while as the visitors during the year numbered somewhat over 75,000, the Museum would seem to be appreciated by the public. The average number of animals in the Garden has been something over 400, representing 130 species, and the Botanic Garden gives a list of 531 species of plants. Attention is called to the fact that the Museum publications represent but a portion of the work of the staff as numerous articles are published in foreign scientific journals.

The Para Museum has just issued as the first of its memoirs, in quarto form, an account by the Director, Dr. Goeldi, of the exploration of the mortuary vaults constructed by a former race of Indians on the banks of the Rio Cunany, and of the pottery found therein. These vaults or pits were about seven feet deep and half that in diameter, closed above by a granite disk, and at the bottom expanding into a somewhat hemispherical chamber in which the 
pottery was found. This consisted of a number of vases and flattened dishes of quaint and graceful shapes decorated with elaborate patterns in red. These are admirably depicted in the plates accompanying the memoir and indicate a very degree of art in the part of their designers.

F. A. L.

\section{RECENT PROGRESS IN THE EXAMINATION OF FOODS AND DRUGS.}

NEW PLANTS AND DRUGS.

Theodore Peckolt has been continuing his work upon the medicinal and economical plants of Brazil (see Berichte d. deutsch Pharm. Ges.). Duyk likewise continues his communications upon Mexican drugs (Bull. Soc. Pharm. Brux., XLIII., and Bull. Comm., XXVIII.). In the consideration of the useful plants of Mexico, J. N. Rose (contribution, U. S. Nat. Herbarium, V., No. IV) treats of the plants of Mexico which are employed for making beverages, seasoning, flavoring, soap, tanning, dyeing as well as those of a strictly medicinal application. J. S. Ward has described some new West African plants in Pharm. Jour., 1900. Several Indian plants have been examined by S. Camphuijo (see Nederl. Tidjschr. v. Pharm., 1899). The arrow poisons of Wagogos are obtained, according to Schellman, by boiling the bark of two trees of the N. O. Euphorbiaceae. Pilocarpus racemosus, of the French Antilles, is given by Rocher as a new source of Jaborandi. The leaves contain 0.6 per cent. of pilocarpine and 0.4 per cent. of jaborine. David Hooper has shown that the ancient eastern medicine, Akakia, is an astringent extract of an acacia. Schumann has added to our knowledge of the kola exported between Senegal and Angola. All kola seeds are wrapped with the leaves of Cola cordifolia. The large seed (nguru) is obtained from Cola vera; whereas the small seed (kotofo) is the product of $C$. acuminata. The natives of Bali also employ the seeds of C. lepidota and $C$. anomala. According to the investigations of Hendrickx and Coremans, the leaves of Theobroma kalagua may be employed as substitutes for kola and cacao.

H. Moeller does not consider that Rheum Franzenbachii furnishes any of the commercial rhubarb. Ergot from rice, cultivated by the
Indians in Northern Wisconsin, has been examined by R. H. Denniston. Heckel and Schlagdenhauffen find quassin and saponin in the seeds of Brucea Sumatrana (N. O. Simarubaceae). These seeds known as kosam seeds are used in China and India for dysentery. Bertrand and Physalix believe the activity to be due to a glucoside which they call kosamin. A new rubber plant of Lagos (Fantumnia elastica) is described by Staff. F. africana (syn. Kicksia africana) does not appear to yield any rubber.

Cathaedulis contains according to Schaer large quantities of caoutchouc, an ethereal oil, alkaloid and tannin. Large edible tubers, called ' native yams' are yielded by Parsonia paddisoni (N. O. Apocynaceae). Piralahy rubber (Madagascar) is the product of Landolphia perieri H. Jumell. Altamassano has extracted from Coniza, one of the Mexican compositæ, a glucoside which he calls lennesine. Several pecies of Polygala (P. violacea St. Hil. and $P$. caroeasana H. B. K.), have been found by Dethan in commercial ipecacuanha. Small jaborandi. leaves have been utilized as an adulterant in coca. A new spurious senna has been described by Greenish while Micko has discovered another false cinnamon bark. This is yielded by an unknown species of Cinnamomum, but does not contain the aromatic cinnamon oil.

\section{PLANT CONSTITUENTS.}

The investigations of Hesse on the Solanaceous alkaloids show that the active principles. of Hyoscyamus are chiefly hyoscyamin with some atropin and hyoscin; while Belladonna root contains an excess of atropine; and Scopola rhizome contains chiefly hyoscin with some atrosin. The two last mentioned bases are found in the scopolamin of commerce.

Hesse finds as a result of an investigation of the various commercial rhubarbs that the Chinese rhubarb contains chrysophanic acid, emodin, rhabarberon and rhein ; Austrian rhubarb (Rheum rhaponticum) and English rhubarb (R. palmatum) contain chrysophanic acid and rhapontin; Rumex nepalensis and $R$. palustris contain chrysophanic acid and nepodin ; Rumex obtusifolia contains chrysophanic acid, nepodin and lopodin. 